\title{
Integrating physiological threshold experiments with climate modeling to project mangrove species' range expansion
}

\author{
KYLE C. CAVANAUGH ${ }^{1,2,3}$, JOHN D. PARKER ${ }^{2}$, SUSAN C. COOK-PATTON ${ }^{2}$, ILKA C. \\ FELLER ${ }^{2}$, A. PARK WILLIAMS ${ }^{4}$ and JAMES R. KELLNER ${ }^{3}$ \\ ${ }^{1}$ Department of Geography, University of California, Los Angeles, 1255 Bunche Hall, Box 951524, Los Angeles, CA 90095, USA, \\ ${ }^{2}$ Smithsonian Environmental Research Center, Smithsonian Institution, Edgewater, MD 21037, USA, ${ }^{3}$ Department of Ecology and \\ Evolutionary Biology, Brown University, Providence, RI 02912, USA, ${ }^{4}$ Lamont-Doherty Earth Observatory, Colombia University, \\ Palisades, NY 10964, USA
}

\begin{abstract}
Predictions of climate-related shifts in species ranges have largely been based on correlative models. Due to limitations of these models, there is a need for more integration of experimental approaches when studying impacts of climate change on species distributions. Here, we used controlled experiments to identify physiological thresholds that control poleward range limits of three species of mangroves found in North America. We found that all three species exhibited a threshold response to extreme cold, but freeze tolerance thresholds varied among species. From these experiments, we developed a climate metric, freeze degree days (FDD), which incorporates both the intensity and the frequency of freezes. When included in distribution models, FDD accurately predicted mangrove presence/absence. Using 28 years of satellite imagery, we linked FDD to observed changes in mangrove abundance in Florida, further exemplifying the importance of extreme cold. We then used downscaled climate projections of FDD to project that these range limits will move northward by $2.2-3.2 \mathrm{~km} \mathrm{yr}^{-1}$ over the next 50 years.
\end{abstract}

Keywords: Avicennia germinans, climate change, ecological thresholds, freeze tolerance, Laguncularia racemosa, range expansion, Rhizophora mangle, species distribution modeling

Received 12 August 2014; revised version received 15 November 2014 and accepted 19 November 2014

\section{Introduction}

A variety of studies have linked changing climate conditions to range shifts (Chen et al., 2011), changes in phenology (Pau et al., 2011), and altered community structure, function, and productivity in terrestrial, marine, and freshwater ecosystems (Parmesan, 2006). These changes highlight the need for accurate predictions of how species and ecosystems will respond to future climate change (Bellard et al., 2012). In response to this need, correlative distribution modeling has become one of the most frequently used tools for predicting the future distributions of species. Correlative models link the presence/absence or abundance of species to environmental variables using statistical techniques (Guisan \& Zimmermann, 2000). These types of models are easy to implement for a wide range of species as they do not require detailed knowledge of the mechanistic processes that control survival and reproduction, they use a commonly available data source, and they can be easily tailored to fit available data (Potter \& Hargrove, 2013). However, correlative distribution models only

Correspondence: Kyle C. Cavanaugh, tel. 703489 4671, fax 310-206-5976, e-mail: kcavanaugh@geog.ucla.edu implicitly consider the processes that limit the potential range of a species. As a result, it is not always clear whether there is a causal relationship between the response and the predictor variables of the model (Meynard \& Quinn, 2007). This can be particularly problematic when automated model selection strategies are applied to a large number of correlated predictor variables. Moreover, these models generally assume that the processes that set range limits are fixed in space and time, an assumption that may be violated when these models are used to predict climate-driven range shifts or to model species with nonequilibrium distributions (Kearney \& Porter, 2009; Buckley et al., 2010).

Another limitation of many distribution models is that they use environmental predictors based on climatic means. However, there is growing recognition that changes in the frequency and intensity of extreme weather events can profoundly impact ecosystems (Jentsch et al., 2007; Lloret et al., 2012; Cavanaugh et al., 2014) and that incorporating measures of climate extremes can improve predictions of species distribution models (Zimmermann et al., 2009). Moreover, including climate variability in species distribution models is important because climate change is expected to impact the frequency of extreme events (Easterling 
et al., 2000; IPCC, 2012). From a organism's point of view, extreme events occur when the acclimation capacities of the organism are exceeded (Gutschick \& BassiriRad, 2003). Therefore, information about the organism's response to environmental conditions is needed to define what constitutes an extreme event.

Because of these limitations, there have been calls for more experimental approaches to studying the impacts of climate change (Thompson et al., 2013; Kreyling et al., 2014). Such experiments provide a mechanistic understanding of the processes controlling a species' distribution, which can be applied to nonequilibrium distributions and/or novel conditions (Kearney \& Porter, 2009). This approach can be used to identify thresholds in the response of organisms to changes in environmental conditions (Kreyling et al., 2014) so that the impacts of extreme events can be better understood. Ideally, these kinds of experiments will be incorporated in a framework that uses a variety of approaches, including distribution modeling, to formulate predictions about how climate change will impact species distributions (Dawson et al., 2011). For example, mechanistic understanding gained from laboratory and field experiments can be used to develop highly proximal predictor variables for correlative models (Kearney \& Porter, 2009).

Understanding how coastal foundation species will respond to climate change is particularly important. Seagrasses, kelps, salt marshes, and mangroves are all foundation species that structure communities by modifying the habitats and resources of other organisms, and therefore have a major influence on ecosystem structure and function (Ellison et al., 2005). These coastal ecosystems are socially and economically important and provide trillions of dollars of value in ecosystem services each year (Costanza et al., 1997).

In coastal wetlands near tropical-temperate transition zones, salt marshes have been displaced by a poleward expansion of tropical and subtropical mangrove trees in recent decades (Stevens et al., 2006; Cavanaugh et al., 2014; Saintilan et al., 2014). Mangroves are limited to tropical and subtropical climates between ca. $30 \mathrm{~N}$ and 40S, while salt marshes dominate more temperate coastlines (Duke et al., 1998). While multiple environmental factors determine mangrove distributions (Duke et al., 1998), cold temperatures are believed to control their poleward limits (Soares et al., 2012). There is evidence that in some regions (e.g., southeast North America) the observed poleward expansion of mangroves is due to a decrease in the frequency of extreme cold events (Cavanaugh et al., 2014). Correlative distribution modeling suggests that mangrove-salt marsh ecotones in many parts of the world may exist near temperaturerelated thresholds, where increasing winter tempera- tures could lead to further mangrove expansion (Osland et al., 2013; Record et al., 2013).

While field observations (Cavanaugh et al., 2014) and distribution models (Osland et al., 2013) have suggested that mangroves exhibit a threshold response to freeze, only a handful of studies have experimentally examined freeze tolerance in mangroves (Markley et al., 1982; Stuart et al., 2007; Pickens \& Hester, 2011). Markley et al. (1982) grew propagules of North American mangrove species in a common garden and found variability in freeze tolerance across species and between different populations of the same species. Stuart et al. (2007) performed controlled laboratory experiments that demonstrated variability in freeze tolerance across five species of North American and Australian mangroves. Neither of these studies was designed to identify freeze tolerance thresholds; they did not utilize a gradient of freeze intensities or durations (see Kreyling et al., 2014). Pickens \& Hester (2011) did examine the response of mangrove propagules and seedlings to three temperature treatments $\left(5.7,2.5\right.$, and $\left.-6.5{ }^{\circ} \mathrm{C}\right)$ and four durations $(2,6,12$, and 24 hours), but this study was limited to early life stages of one species of mangroves, Avicennia germinans.

In this study, we combined laboratory experiments, satellite-based observations, and climate modeling to (i) identify specific, temperature-related controls of mangrove range limits and (ii) forecast future poleward migration of three species of mangroves in Florida. We experimentally examined the freeze tolerance of the three dominant species of mangrove native to Florida, A. germinans (black mangrove), Laguncularia racemosa (white mangrove), and Rhizophora mangle (red mangrove). We then incorporated the mechanistic understanding derived from these experiments to identify the climate threshold controlling the range limit of each of the three species. We tested the relevance of these climate thresholds by examining the response of mangrove stands to past freeze events using 28 years of Landsat satellite imagery. Finally, we used downscaled climate model projections to forecast the future range limit and estimate the future rate of poleward migration for each species.

\section{Materials and methods}

\section{Study area}

Our study area included wetlands along the Atlantic coasts of Florida, Georgia, and South Carolina, USA from 26 to $33 \mathrm{~N}$. The current northern limit of mangroves in eastern North America is located around $30 \mathrm{~N}$, just north of St. Augustine FL (Williams et al., 2014). Salt marshes dominate the more temperate climates to the north, whereas mangroves and salt marsh coexist in an ca. $2^{\circ}$ ecotone to the south $(28-30 \mathrm{~N})$. South of $28 \mathrm{~N}$, mangroves typically dominate coastal wetlands 
(Kangas \& Lugo, 1990). Mangrove wetlands in Florida are dominated by $1-3$ species of short- to medium-sized trees, including black, red, and white mangrove. Recently, Williams et al. (2014) identified the northernmost individuals in Florida from each of the three mangrove species. The northernmost black mangrove was found at $30.11 \mathrm{~N}, 81.37 \mathrm{~W}$; the northernmost red mangrove was found at $29.94 \mathrm{~N}, 81.32 \mathrm{~W}$; and the northernmost white mangrove was found at $29.73 \mathrm{~N}, 81.24 \mathrm{~W}$.

\section{Determining physiological threshold responses of mangroves to severe cold}

In June 2013, we collected branches from black, red, and white mangroves in Avalon State Park (27.55 N, 80.33 W). To maintain the physiological integrity of the branches, we removed a long branch from each tree, cut off the top ca. $15 \mathrm{~cm}$ of the branch under water, and placed this tip directly into floral water tubes. We then placed branches in a freezer for 4.5 hour trials, using a thermoregulator (Aqua Logic EC115R; Aqua Logic, Inc., San Diego, CA, USA) to maintain a steady temperature. We conducted a total of 21 different trials, with average minimum temperatures in each trial ranging from -0.2 to $-11.0^{\circ} \mathrm{C}$ (recorded with $\mathrm{HOBO}$ data loggers). We included branches from 20 individuals per species in almost all trials ( $N=420$ blacks, 418 reds, and 360 whites), except for the $-5.3^{\circ} \mathrm{C}$ trial, which had 18 red mangrove individuals and zero white mangroves, and the $-4.2{ }^{\circ} \mathrm{C}$ and one of the $-6.7^{\circ} \mathrm{C}$ trials, which also had zero white mangroves.

To assess susceptibility to cold, we measured photoinactivation or the change in chlorophyll fluorescence yield $(Y)$ after a freeze event. Change in yield is a common freeze tolerance metric (Cavender-Bares et al. 2005; Pérez et al., 2014) that correlates with other freeze tolerance metrics (Boorse et al. 1998). We measured yield before and after the freeze treatment with a miniPAM (Photosynthetic Yield Analyzer; Walz, Mess- und Regeltechnik, Effeltrich, Germany) and quantified photoinactivation as $1-Y_{\text {post }} / Y_{\max }$ (Pérez et al., 2014). Photoinactivation thus ranged from zero (no loss of photosynthetic function) to one (complete loss of photosynthetic function). Because yield is sensitive to the light history of leaves, temperature, and current light conditions, we sampled analogous leaves across individuals. We marked leaves, so we could repeat measurements after the cold treatment at the exact same leaf location and orientation, and allowed branches to equilibrate to uniform laboratory light and temperature conditions for at least 1 hour before assessing yield. We analyzed photoinactivation with average minimum temperature and species identity as predictors using general linear models with logistic link functions (logistic regression). Species identity was incorporated into the models using dummy variables with white mangrove being the base case. We assessed the effect of species on freeze tolerance by examining the significance of the dummy variable coefficients.

\section{Linking mangrove physiological thresholds to range limits}

We created a series of models to relate mangrove presence/ absence to modern climate. We characterized modern climate using gridded daily minimum temperature $\left(T_{\min }\right)$ data for 1981-2010 from Maurer et al. (2002). The original resolution of the data was $1 / 8^{\circ}$, which we statistically downscaled to 30 arc second (ca. $800 \mathrm{~m}$ ) geographic resolution (see Appendix S1 for more details). We then developed a mangrove presence/ absence data set with the same spatial resolution as our climate data $(800 \mathrm{~m})$. Our analysis was restricted to cells that contained estuarine and marine wetlands according to the US Fish and Wildlife Service National Wetlands Inventory. Mangrove presence/absence in each cell was determined using data from two mangrove distribution data sets (Spalding et al., 2010; Giri et al., 2011b). A composite of the two data sets was used to minimize errors of omission. The available mangrove presence/absence data sets did not differentiate among species, and so all three species of mangroves were grouped together for this analysis. From the daily climate data, we calculated mean daily $T_{\min }$ mean winter (December-February) $T_{\text {min }}$, mean winter minimum $T_{\text {min }}$, and the overall minimum $T_{\text {min }}$ of the record for each grid cell for the time period from 1980 to 2010.

Based on the results from our freeze tolerance experiments, we also developed a new winter severity index, freeze degree days (FDD). First, we used the modeled logistic relationship between photoinactivation (from the laboratory analysis) and freeze intensity to identify the temperature that corresponded to $10 \%$ photoinactivation (Fig. 1). A cut-off of $10 \%$ photoinactivation was used to identify the base temperature because it would be more likely to capture the impacts of minor freezes than a threshold based on the inflection point of the sigmoid curve (i.e., the temperature corresponding to $50 \%$ photoinactivation). We used the threshold temperature of the most tolerant species, A. germinans, which resulted in a threshold of $-3.2{ }^{\circ} \mathrm{C}$. Selecting this base temperature is akin to calculating

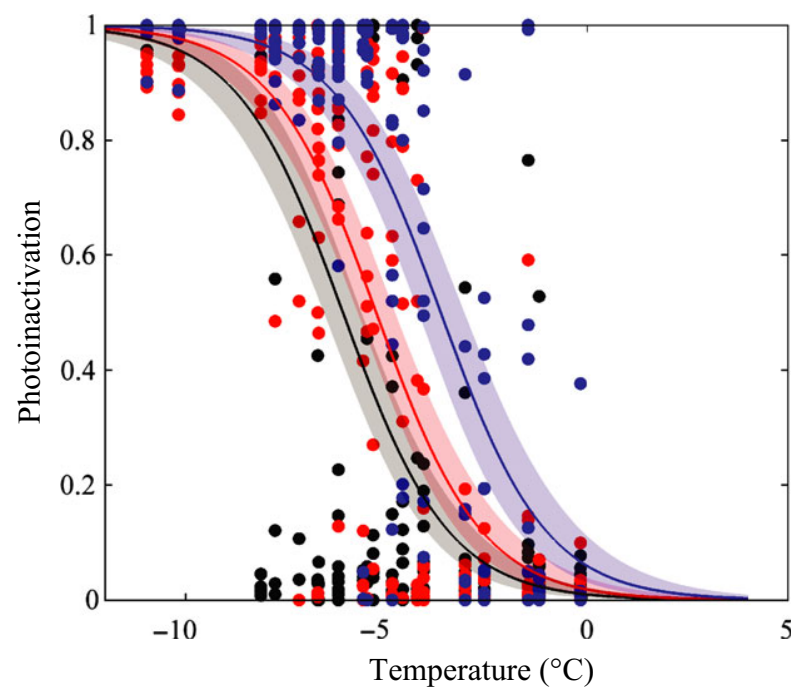

Fig. 1 Relationship between temperature treatment and photoinactivation for branches from three mangrove species from laboratory studies. Black lines represent Avicennia germinans, red lines Rhizophora mangle, and blue lines Laguncularia racemosa. Shaded regions represent $95 \%$ confidence interval. 
a base temperature for calculating growing degree-days; however, in that case, the goal is to identify the temperature below which plant growth and development ceases (Yang et al., 1995). FDD was calculated as,

$$
\mathrm{FDD}=\max \left(\left[0 T_{\text {base }}-T_{\min }\right]\right),
$$

with $T_{\text {base }}$ being the temperature that corresponded to $10 \%$ photoinactivation in the above experiment $\left(-3.2^{\circ} \mathrm{C}\right)$. We examined the sensitivity of our results to varying $T_{\text {base }}$ from 0 to $-4{ }^{\circ} \mathrm{C}(0-35 \%$ photoinactivation). Because our mangrove presence/absence data did not differentiate species, we used the threshold temperature of the most tolerant species, A. germinans, to calculate FDD. The average annual FDD was calculated for each cell between 1980 and 2010. Finally, we calculated the annual number of days below the threshold to distinguish the impact of freeze frequency from that of freeze intensity. The daily $T_{\min }$-based temperature metrics were highly correlated (the absolute value of the mean and minimum bivariate correlations were 0.93 and 0.84 , respectively; Table S1), so we developed single predictor models and used Akaike's information criterion (AIC) to measure the relative quality of each model.

The FDD-based mangrove presence/absence model had the lowest AIC and so was selected as the optimal model (Fig. 2). Relative likelihood that another model would minimize information loss, calculated following (Burnham \& Anderson, 2002),

$$
\exp \left(\left(\mathrm{AIC}_{\min }-\mathrm{AIC}_{i}\right) / 2\right),
$$

was $\ll 0.001$ for all models. To further test the idea that FDD influences the northern range limit for mangroves, we compared changes in mangrove area between summers to the cumulative FDD during the intervening winter. We used time series of mangrove area from 1984 to 2011 derived from Landsat 5 Thematic Mapper (TM) imagery collected each summer (Cavanaugh et al., 2014). Imagery for 1985, 1998, 2004, and 2010 was not available due to cloud cover. Using a handheld GPS, we identified areas in Avalon State Park (where branches were collected for laboratory analysis, $27.55 \mathrm{~N}, 80.33 \mathrm{~W}$ ) and Sebastian Inlet State Park $(27.85 \mathrm{~N}, 80.45 \mathrm{~W})$ that contained large $(>30 \mathrm{~m} \times 30 \mathrm{~m})$, monospecific stands of red, black, and white mangroves in close proximity to each other. We then identified the Landsat pixels that were within each outlined stand such that the Landsat pixels represented pure speciesspecific stands of mangrove trees. We then calculated each year's cumulative FDD value for those pixels. For each of the three stands in each of the two sites, we compared the annual change in mangrove area between successive summers to the cumulative FDD of the intervening winter for each year that experienced a freeze event. Freeze events occurred at the two sites in nine of the years for which we had satellite imagery. However, minimum temperatures fell below the FDD base temperature $\left(-3.2{ }^{\circ} \mathrm{C}\right)$ in only one (1989) of those 9 years. In that year, the minimum temperature was $-4.5^{\circ} \mathrm{C}$ at the Sebastian Inlet site and $-5.3{ }^{\circ} \mathrm{C}$ at the Ft. Pierce site. In the other 8 years that experienced freezes, cumulative FDD was 0. As we did not have a range of FDD values, we could not justify fitting a curve relating change in mangrove area to FDD (i.e., the approach we used to analyze the laboratory experiment). Instead, we grouped the data from the two sites and performed an ANOVA to compare years that experienced a freeze event, but had zero FDD to years with FDD $>0$. We used Bonferroni-adjusted $t$-tests to compare species-specific responses.

The current latitudinal range limits for black, red, and white mangroves were used to infer the climate envelope for each species. We used field surveys to identify the northernmost stand of black, red, and white mangroves where stand equaled a contiguous group of $>10$ trees. Note that we did not use the range limits identified by Williams et al. (2014) as they represented the locations of isolated individuals. The FDD value at the location of the northernmost stands of black, red, and white mangroves was inferred to be the threshold for the presence of each of the three mangrove species.

\section{Projections of future mangrove range limits}

We used downscaled climate projections to forecast future range limits for each species. To characterize future climatic conditions, we used daily $T_{\min }$ from 2030 to 2060 from an ensemble of 21 general circulation models (GCMs) as part of the 5th phase of the Coupled Model Intercomparison Project (CMIP5), developed for the most recent report by the Intergovernmental Panel on Climate Change (IPCC). We considered the most severe emissions scenario (RCP 8.5) for each GCM to characterize the upper bound on projected trends (e.g., Scoccimarro et al., 2013). We alternatively projected future range limits for each species using the RCP 4.5 scenario. As with the observed $T_{\min }$ data, we statistically downscaled the already downscaled $1 / 8^{\circ}$ data of each GCM (Maurer et al., 2007 ) to a resolution of 30 arc seconds. We then identified grid cells where the projected climate data crossed the mangrove presence FDD threshold for each species. We also forecasted future range limits for each species using thresholds based on the other climate variables [mean daily $T_{\min }$, mean winter (December-February) $T_{\min }$, mean winter minimum $T_{\min }$ minimum $T_{\min }$ and mean number of days less than $\left.3.2^{\circ} \mathrm{C}\right]$.

\section{Results}

All three species of mangroves demonstrated a threshold response to freezing temperatures, with large reductions in performance occurring between -2 and $-6{ }^{\circ} \mathrm{C}$ (Fig. 1). Freeze tolerance varied among species in the laboratory experiments (Table 1). Black mangroves were the most freeze tolerant and white mangroves were the least tolerant. This result matched the observation that black mangroves have the most northward distribution in Florida, followed by red mangroves and then white mangroves (Williams et al., 2014).

We used these freeze response curves to develop our mangrove-specific winter severity index, FDD, with $T_{\text {base }}=-3.2^{\circ} \mathrm{C}$. There was a significant relationship between all five of our temperature metrics and 

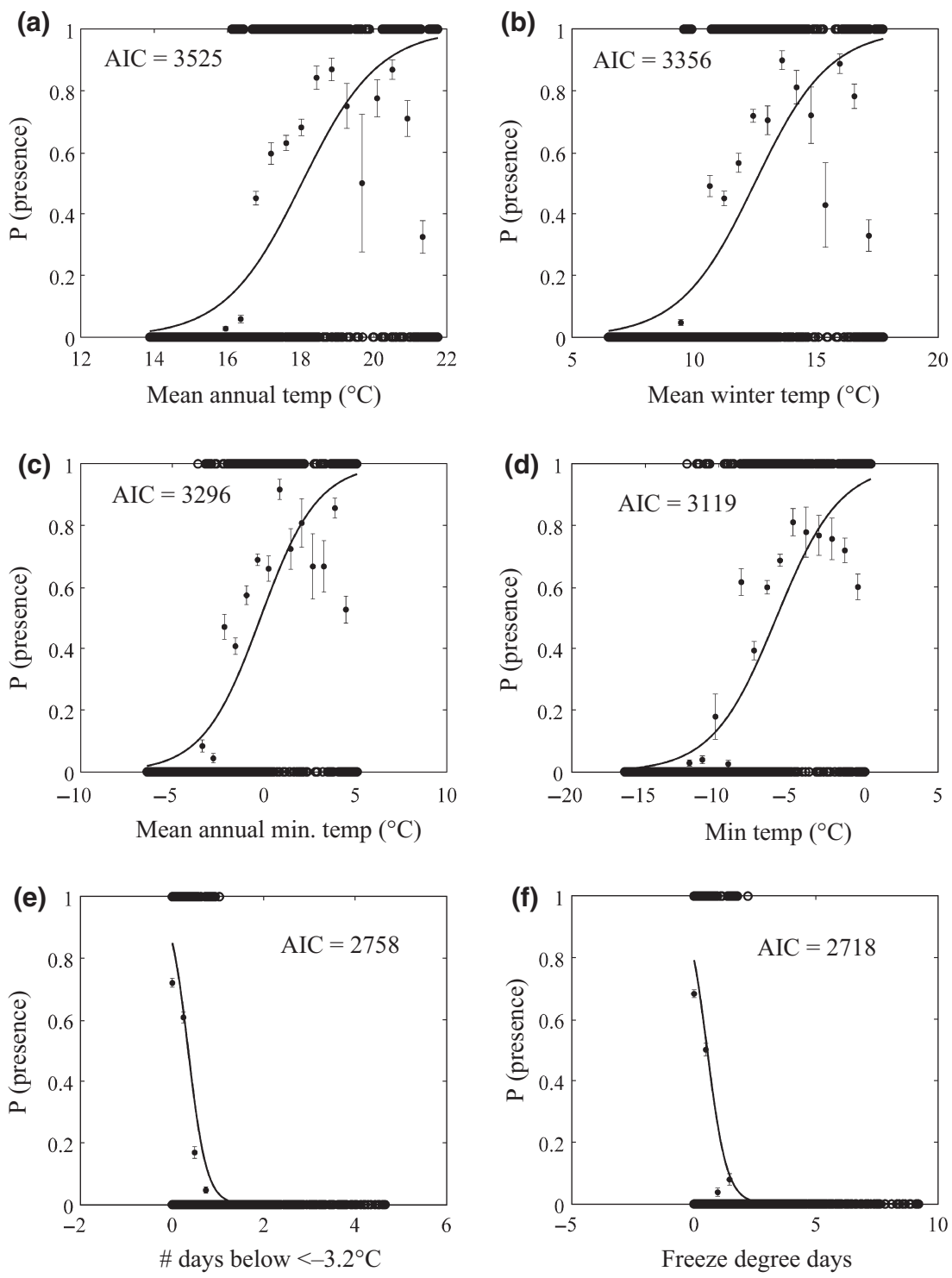

per year

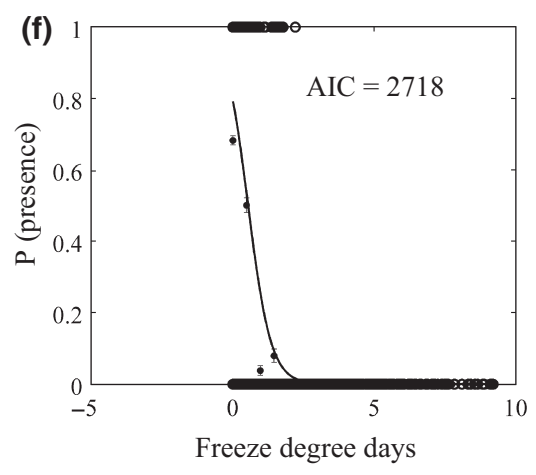

per year

Fig. 2 Logistic relationships between mangrove presence/absence and (a) mean annual temperature, (b) mean winter temperature, (c) mean annual minimum temperature, (d) minimum temperature, (e) number of days less than $-3.2{ }^{\circ} \mathrm{C}$ per year and (f) degree days less than $-3.2{ }^{\circ} \mathrm{C}$ per year. Closed circles and error bars give the mean and standard error of presence/absence data separated into 20 bins. Lines give the logistic regressions for the relationships. Solid lines are significant at $P<0.01$. Open circles give the raw presence/ absence data.

Table 1 Results from dummy variable logistic regression comparing photoinactivation to temperature treatment and species type in laboratory studies

\begin{tabular}{lcccccc}
\hline Variable & Estimate & $\begin{array}{l}\text { Std. } \\
\text { error }\end{array}$ & $\mathrm{df}$ & $t$ & $P$ \\
\hline $\begin{array}{l}\text { Intercept (species }- \\
\text { white) }\end{array}$ & -2.77 & 0.35 & 594 & -7.9 & $<0.01$ \\
Temperature & -0.76 & 0.06 & 594 & -11.7 & $<0.01$ \\
Species - black & -4.62 & 0.29 & 594 & -6.3 & $<0.01$ \\
Species - red & -3.99 & 0.29 & 594 & -4.2 & $<0.01$ \\
\hline
\end{tabular}

mangrove presence $(P<0.01$ for all logistic models; Fig. 2). However, mean annual FDD was the temperature variable that best predicted mangrove presence based on AIC (Fig. 2). As a result, we used FDD to infer the current temperature-related threshold for mangrove presence and to predict future mangrove range limits for black, red, and white mangroves. When the threshold for calculating FDD was varied from 0 to $-4.0^{\circ} \mathrm{C}$, AIC varied a minor amount, but still remained lower than for the other temperature variables (Table S2). 
Our Landsat analysis demonstrated that years when FDD was $>0$ experienced significantly higher loss of mangrove area than years that experienced minor freezes where minimum temperature was greater than $-3.2^{\circ} \mathrm{C}$ (Fig. 3; Table 2). Some species-specific variability in freeze tolerance was observed during the extreme freeze event, with black mangroves experiencing the least amount of loss (Fig. 3).

The northernmost stand of black mangroves was located at $29.92 \mathrm{~N}, 81.31 \mathrm{~W}$; the northernmost stand of red mangroves was located about $23 \mathrm{~km}$ further south at $29.73 \mathrm{~N}, 81.24 \mathrm{~W}$; and the northernmost stand of white mangroves was located about $7 \mathrm{~km}$ south of the red mangroves at $29.66 \mathrm{~N}, 81.22 \mathrm{~W}$ (Fig. 4). At these current range limits of black, red, and white mangroves, the average FDD per year between 1980 and 2010 were 2.1, 1.5, and 1.5, respectively (Fig. 4). Based on RCP 8.5 climate projections of where these FDD

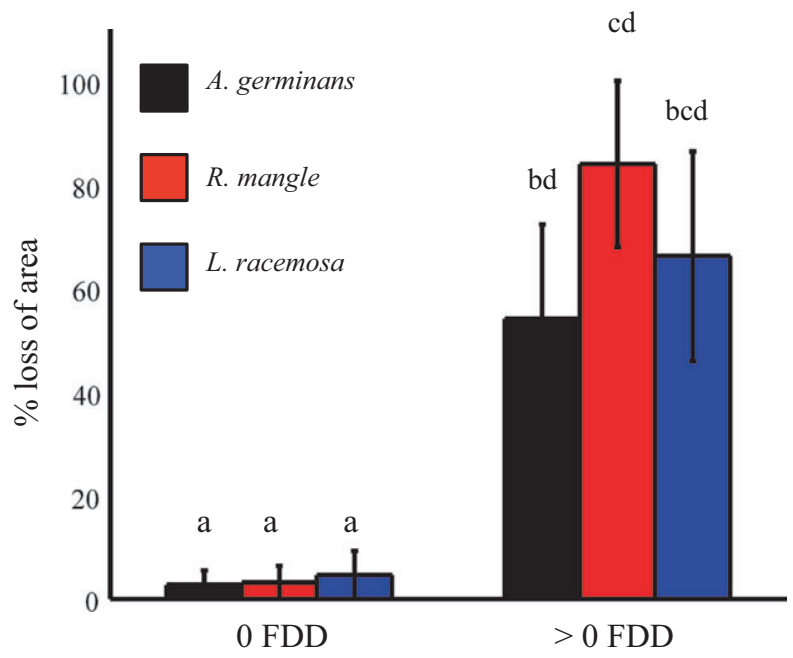

Fig. 3 Comparison of the impact of minor freezes with 0 freeze degree days (FDD) to hard freezes with FDD $>0$ for stands of black, red, and white mangroves. $n=16$ for each species in the 0 FDD case and $n=2$ for each species in the $>0$ FDD case. Unique letters denote significant differences based on Bonferroni-adjusted $t$-tests. Error bars give the interquartile range of the responses.

Table 2 Results from analysis of variance comparing the impact of minor freezes with 0 freeze degree days (FDD) to hard freezes with FDD $>0$ for stands of black, red, and white mangroves. Data for this analysis came from Landsat observations of change in mangrove cover between successive summers

\begin{tabular}{lrrrrl}
\hline Source & \multicolumn{1}{l}{ SS } & \multicolumn{1}{c}{ df } & \multicolumn{1}{c}{ MS } & \multicolumn{1}{l}{$F$} & \multicolumn{1}{l}{$P$} \\
\hline FDD & 23133.79 & 5.00 & 4626.76 & 61.03 & $<0.01$ \\
Error & 3638.83 & 48.00 & 75.81 & & \\
Total & 26772.63 & 53.00 & & & \\
\hline
\end{tabular}

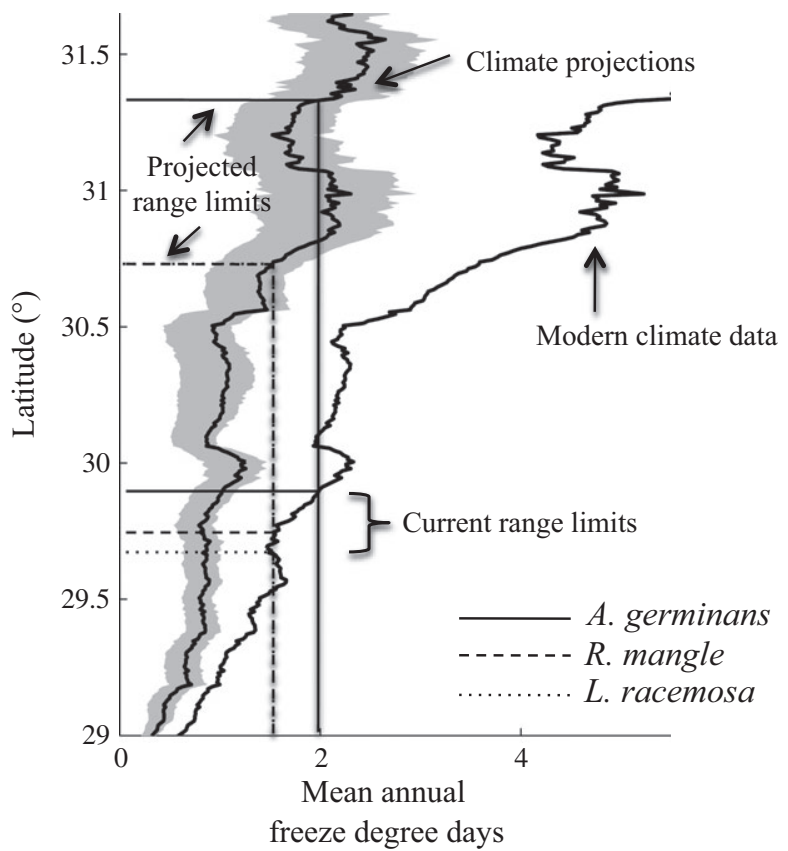

Fig. 4 The mean annual freeze degree days (FDD) for modern climate (1980-2010) and for climate projections (2030-2060) along the Atlantic coastlines of Florida and Georgia from 29 to 31.5 N. The current northernmost stands of Avicennia germinans, Rhizophora mangle, and Laguncularia racemosa are shown by the lower horizontal solid, dashed, and dotted lines. Based on the mean annual FDD at the current range limits (2.1 for A. germinans and 1.5 for R. mangle and L. racemosa), we project future range limits in 2060 (upper horizontal solid, dashed, and dotted lines). The upper dotted and dashed lines showing the projected range limits of $R$. mangle and L. racemosa overlap and so are difficult to distinguish from one another. The shaded area around the climate projection line gives the interquartile range of the 21 climate projection models we examined.

thresholds will occur in 2060, we project that the northern range limits for black, red, and white mangroves on the Atlantic coast of North America will be located at $31.33 \mathrm{~N}$ [interquartile projections: $(31.20 \mathrm{~N}, 31.50 \mathrm{~N})$ ], $30.71 \mathrm{~N}(30.55 \mathrm{~N}, 31.35 \mathrm{~N})$, and $30.71 \mathrm{~N}(30.55 \mathrm{~N}, 31.35$ $\mathrm{N}$ ), respectively (Figs 4 and 5). These projections correspond to northward migration rates of $3.2(2.9,3.7), 2.2$ $(1.9,3.7)$, and $2.4(2.0,3.8) \mathrm{km} \mathrm{yr}^{-1}$. Using the other climate metrics [mean daily $T_{\min }$, mean winter (December-February) $T_{\min }$, mean winter minimum $T_{\min }$ minimum $T_{\min }$ and mean number of days less than $-3.2{ }^{\circ} \mathrm{C}$ ] resulted in range limit projections that ranged from $82 \mathrm{~km}$ south to $33 \mathrm{~km}$ north of the projections made using FDD (Table S3). As expected, range limit models built from RCP 4.5 climate projections predict slightly slower northward migration of range limits, reaching $31.23 \mathrm{~N}$ by 2060 [interquartile projections: $(30.69 \mathrm{~N}, 31.50 \mathrm{~N})], 30.55 \mathrm{~N}(30.50 \mathrm{~N}, 31.31 \mathrm{~N})$, and $30.55 \mathrm{~N}(30.50 \mathrm{~N}, 31.31 \mathrm{~N})$, respectively (Fig. S1). 
(a) A. germinans

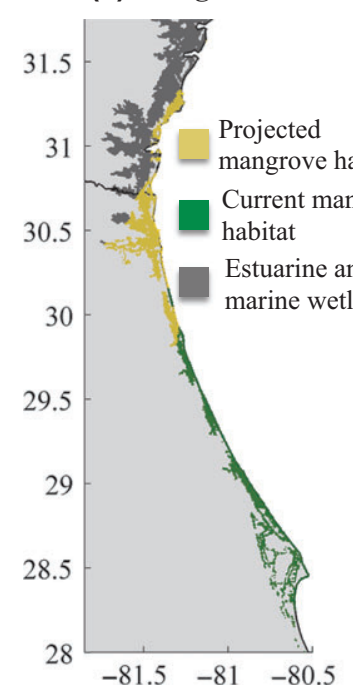

(b) R. mangle

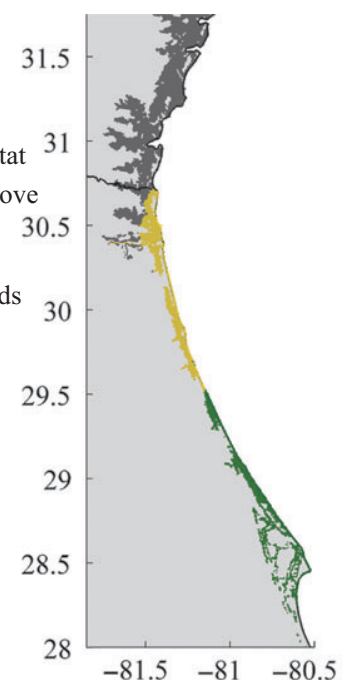

(c) L. racemosa

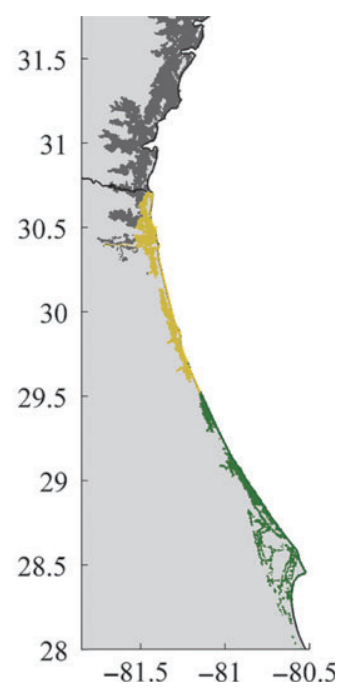

Fig. 5 Map of US southeastern Atlantic coastline showing the modeled current and projected (2060) extents of (a) Avicennia germinans, (b) Rhizophora mangle, and (c) Laguncularia racemosa. Projected range limits are based on the mean of the ensemble CMIP 5 RCP 8.5 projections.

\section{Discussion}

We used controlled laboratory studies to identify physiological thresholds in mangroves and develop a simple climate-based model to identify the climatic variable (FDD) that sets the poleward range limits for the three species of mangroves in North America. We then validated the role of FDD using Landsat observations of annual changes in mangrove area on landscape scales in response to cold winters. Finally, a simple climatebased modeling approach was used to project future movement of these range limits. This approach of integrating controlled laboratory studies with multi-decadal satellite observations and climate models has the potential to improve predictions of the impacts of climate change on ecosystems (Dawson et al., 2011; Kreyling et al., 2014). Biological responses to temperature changes can be nonlinear and characterized by thresholds (Gutschick \& BassiriRad, 2003). Controlled laboratory experiments provide a means for identifying these thresholds. However, these kinds of experiments do not capture the complexity of real systems and so results can be difficult to scale up to the ecosystem level (Kreyling et al., 2014). Field observations and experiments can provide a way to validate and scale up these laboratory results. These can consist of observations of how the system has responded to past changes (e.g., the retrospective satellite-based approach used here) or of manipulative field experiments (e.g., Beier et al., 2004; Loik et al., 2004; Lloret et al., 2005). Modeled climate projections can then be used to infer the response of the ecosystem to future environmental changes.
However, it is important that climate projections, which typically have coarse spatial resolutions, are downscaled so they can provide predictions at scales that are ecologically meaningful and relevant to local management (i.e., county and state levels).

We found that northern range limits of mangroves in southeast North America are controlled by both frequency and intensity of discrete, extreme cold events. Previous studies characterized the impacts of freeze events on mangrove structure and mortality on local scales (Stevens et al., 2006; Ross et al., 2009). A number of studies have documented the impacts of an unusual series of freezes that occurred in the 1980s and led to massive amounts of mangrove mortality across the southeastern United States (Lonard \& Judd, 1991; Montague \& Odum, 1997; Stevens et al., 2006; Giri et al., 2011a). More recent work has demonstrated that extreme cold is more important than mean temperature in controlling the abundance and distribution of mangroves on regional scales (Osland et al., 2013; Cavanaugh et al., 2014). For example, Cavanaugh et al. (2014) demonstrated that a decrease in the frequency of extreme cold events between 1984 and 2010 corresponded to regional increases in mangrove cover over that same time period. Osland et al. (2013) found that the average lowest temperature of the year, a measure of severity, was a strong predictor of mangrove presence and abundance. We built off of these studies by creating a new metric that integrates the frequency and intensity of extreme cold events, FDD. This metric was a slightly better predictor of mangrove presence/ 
absence than mean annual minimum temperature, a measure of freeze severity, or the average number of days below $-3.2^{\circ} \mathrm{C}$, our measure of freeze frequency. FDD is correlated with the other winter severity metrics evaluated; however, we observed differences of $11-73 \mathrm{~km}$ when we compared projections made with FDD to those made with mean annual minimum temperature and the average number of days below $-3.2{ }^{\circ} \mathrm{C}$ (Table S3). These differences are small relative to the full distributional range of mangroves, but they are comparable to the differences between the current range limits of black, red, and white mangrove species. Although we do not have the data to evaluate the performance of these different predictions, our FDD model has a stronger theoretical grounding as it can capture the effect of years that experience multiple extreme cold events. Most of the winters that were characterized as 'severe freeze seasons' by the Florida Crop and Livestock Service experienced sustained cold spells or multiple distinct freeze events (Miller \& Downton, 1993). Identifying the specific proximate controls of species distributions should facilitate more accurate predictions of how future climate change will alter species distributions (Buckley et al., 2010), particularly for systems that demonstrate nonlinear and threshold dynamics.

Our FDD metric was developed using mechanistic knowledge gained from controlled laboratory studies and validated using field observations of landscapescale responses of mangroves to past freeze events. Previous controlled experimental tests of mangrove freeze tolerance suggest that cold tolerance varies among species (Markley et al., 1982; Stuart et al., 2007; Cook-Patton et al., in review), life stages (Pickens \& Hester, 2011), and populations (Markley et al., 1982; Cook-Patton et al., in review). However, these studies did not examine the response of different species of adult mangroves along a gradient of temperature treatments, so they may not be optimally useful when deriving species-specific thresholds in mangrove freeze tolerance. In our experiments, all three species of mangroves exhibited a threshold response to decreasing temperatures (Fig. 1). Our satellite observations of the impacts of past freeze events also provide evidence for a threshold response of mangroves to freeze on landscape scales. Mangrove stands were relatively unaffected by minor freezes where temperatures remained above $-3.2^{\circ} \mathrm{C}$ (Fig. 3). However, stands experienced large losses in area when temperatures fell below this threshold.

The laboratory studies of species-level variability in freeze tolerance matched the latitudinal distribution of mangroves in our study area. The most freeze-tolerant species in our experiments, black mangroves, has the northernmost distribution, while the least freeze-tolerant species, white mangroves, has the southernmost range limit. In addition, the black mangrove stands showed the highest levels of freeze tolerance in the Landsat analyses. However, we were not able to detect significant difference between red and white mangroves in the Landsat analyses. This may be due to the fact that there were very few extreme freeze events at our field sites (only one winter experienced a minimum temperature less than $-5{ }^{\circ} \mathrm{C}$ ), so there are higher levels of uncertainty regarding the landscape-scale effects of these severe freezes. In addition, there is evidence that effect size, that is the impact of a given treatment, in climate manipulation experiments decreases with spatial scale due to an increasing number of influential processes (Leuzinger et al., 2011). For example, microenvironments and microclimates make some locations more habitable than would be expected from a geographically gridded climate product. As a result, the impact of severe freeze events might be more spatially heterogeneous than would be expected from gridded climate data.

While red mangroves are found $7 \mathrm{~km}$ further north than white mangroves (ca. $7 \mathrm{~km}$ ), the average FDD at both range limits is the same (1.5). The small difference in range limits of these species may be caused by the differences in freeze tolerance identified by our experimental results. It is possible that there is in fact a small difference in FDD between the locations of the red and white mangrove range limits, but our downscaled climate data did not have sufficient accuracy to detect a difference. On the other hand, if the climatic conditions at these two locations are the same, the difference in range limits could be due to a process such as variability in dispersal capabilities (Rabinowitz, 1978). The current range limit of black mangroves is about 23 and $30 \mathrm{~km}$ north of the respective range limits of red and white mangroves. However, the range limit of black mangroves was characterized by a higher FDD per year (2.1) than the range limit for reds and whites (1.5 in both cases). The nature of the threshold response of mangroves to freezes suggests that small differences in freeze frequency and intensity could dictate a given site's suitability for individual species, highlighting the value of considering high-resolution climate data sets when possible. Figure 4 indicates a relatively steep gradient in FDD between the range limits of red (29.73 N) and black (29.92 N) mangroves. The shape of the current FDD profile (Fig. 4) provides insight into the potential for range limit migration (i.e., range infilling) under current climatic conditions. For example, at 30.1 $\mathrm{N}$, the mean average FDD per year during 1981-2010 is below 2.1, suggesting that black mangrove stands may be able to persist at this latitude in the current climate if 
they were able to disperse and establish in suitable habitat there. This process may be occurring, as there has been a recent account of an individual black mangrove shrub at $30.1 \mathrm{~N}$ (Williams et al., 2014).

We project that over the next 50 years, if not limited by dispersal or the availability of suitable habitat, the northern range limits of black, red, and white mangroves will move north by about 160, 110, and $120 \mathrm{~km}$, respectively. This corresponds to migration rates of 3.2, 2.2, and $2.4 \mathrm{~km} \mathrm{yr}^{-1}$ for black, red, and white mangroves. Williams et al. (2014) compared observations of the northernmost mangrove individuals for each species from 2007 to surveys conducted in 2013 and estimated hypothetical migration rates of 4.5, 3.7, and $1.3 \mathrm{~km} \mathrm{yr}^{-1}$, respectively for black, red, and white mangroves. These are short-term changes that almost certainly do not reflect long-term migration rates due to local climate oscillations, dispersal variability, and other stochastic processes. In a meta-analysis of range shifts observed for a variety of animal species over the course of 8-50 years, Chen et al. (2011) found that the median rate of poleward movement was $1.69 \mathrm{~km} \mathrm{yr}^{-1}$. It is surprising that the observed (Williams et al., 2014) and estimated (this study) migration rate of mangroves would be higher than that of many animal species, given that model predictions and observations suggest that changes to the range limits of trees in response to climate change are slow and largely stochastic (Clark et al., 2003). One explanation for rapid mangrove expansion is that water-dispersed plants such as mangroves often can travel further than those dispersed by wind or animals (Ridley, 1930). There is also a large amount of suitable mangrove habitat (i.e., tidal saline wetlands) in our study area, which could facilitate mangrove expansion. Competition with existing salt marsh vegetation has the potential to modulate the poleward expansion of mangroves, but mangroves appear to be competitively dominant in areas where abiotic conditions are suitable (Kangas \& Lugo, 1990). We do not address the impacts of future sea-level rise in this paper as we were focused on poleward rather than landward changes to mangrove ranges. However, that process has the potential to alter the availability of suitable habitat. Landward expansion of mangroves due to sea-level rise has already been documented in Baja California (López-Medellín et al., 2011), the US Gulf Coast (Krauss et al., 2011), and the east coast of Australia (Rogers et al., 2006). If landward migration of mangroves keeps pace with shoreline erosion, then the poleward movement of mangroves' range limits may not be impacted directly by sea-level rise. However, coastal development may eliminate the potential for landward migration in some areas, which could reduce the availability of suitable habitat and slow migration rates. While this paper focuses on regional changes in mangrove range limits, local abiotic factors such as salinity, inundation frequency, and nutrient availability will certainly control mangrove suitability on smaller scales.

Theoretically, including mechanistic understanding into distribution models should improve predictions of responses to climate change (Buckley et al., 2010). A possible next step would be to develop a fully mechanistic model of mangrove distributions. To do this, more detailed data on the functional traits of mangroves are needed. For example, we have identified freeze tolerance thresholds at the branch and leaf level; however, this experimental gradient approach has not yet been used to identify temperature thresholds for seedlings or whole adult plants. Further insight into the physiological response of mangroves to cold could be gained through experiments that decouple the effects of freezing intensity and freezing duration. There is also variability in the mechanisms by which various species of mangroves recover from extreme cold events. For example, A. germinans has the ability to resprout after parts of the plant have been killed by freeze, but $R$. mangle does not (Sherrod \& McMillan, 1985). This characteristic could impact the recovery of mangrove populations in ways not captured by branch and leaf-scale freeze tolerance experiments. Rhizophora mangle would have to rely on dispersal from surviving populations to recolonize areas after disturbance events, which could delay range infilling. There are also questions about how cold impacts plant growth and reproduction. There is evidence of geographic variability in traits related to freeze tolerance in some species of mangroves (Cook-Patton et al., in review), which also could be incorporated into mechanistic models.

While the frequency and intensity of cold events appear to set the poleward range limit of mangroves in southeastern North America, it is likely that other factors such as precipitation, ocean circulation, sea surface temperatures, atmospheric aridity, geomorphic setting, and controls on dispersal will play important roles in other parts of the world (Stuart et al., 2007; Quisthoudt et al., 2012; Saintilan et al., 2014). For example, freezes are rare at the arid poleward range limits of mangroves in Baja California and Peru (Quisthoudt et al., 2012). In addition, (Wilson \& Saintilan, 2012) found that the current poleward range limit of Rhizophora stylosa on the east coast of Australia is well within the thermal tolerance limits of that species. If mechanistic niche models are to be applied in other regions, we will need additional data on salinity tolerance, water, light, and nutrient requirements, and other biophysical characteristics across the different life stages of mangroves. 


\section{Acknowledgements}

Funding for this work was provided by the NASA Climate and Biological Response Program (NNX11AO94G) and the NSF Macrosystems Biology Program (EF 1065821 and 1065098). Thanks to Mike Lehmann and Loraé Simpson for field and laboratory assistance.

\section{References}

Beier C, Emmett B, Gundersen P et al. (2004) Novel approaches to study climate change effects on terrestrial ecosystems in the field: drought and passive nighttime warming. Ecosystems, 7, 583-597.

Bellard C, Bertelsmeier C, Leadley P, Thuiller W, Courchamp F (2012) Impacts of climate change on the future of biodiversity. Ecology Letters, 15, 365-377.

Boorse GC, Bosma TL, Meyer AC, Ewers FW, Davis SD (1998) Comparative methods of estimating freezing temperatures and freezing injury in leaves of chaparral shrubs. International Journal of Plant Sciences, 159, 513-521.

Buckley LB, Urban MC, Angilletta MJ, Crozier LG, Rissler LJ, Sears MW (2010) Can mechanism inform species' distribution models? Ecology Letters, 13, 1041-1054.

Burnham KP, Anderson DR (2002) Model Selection and Multimodel Inference: A Practical Information-Theoretic Approach. Springer, New York, NY.

Cavanaugh KC, Kellner JR, Forde AJ, Gruner DS, Parker JD, Rodriguez W, Feller IC. (2014) Poleward expansion of mangroves is a threshold response to decreased frequency of extreme cold events. Proceedings of the National Academy of Sciences, 111, 723-727.

Cavender-Bares J, Cortes P, Rambal S, Joffre R, Miles B, Rocheteau A (2005) Summer and winter sensitivity of leaves and xylem to minimum freezing temperatures: a comparison of co-occurring Mediterranean oaks that differ in leaf lifespan. New Phytologist, 168, 597-612.

Chen I-C, Hill JK, Ohlemüller R, Roy DB, Thomas CD (2011) Rapid range shifts of species associated with high levels of climate warming. Science, 333, 1024-1026.

Clark JS, Lewis M, McLachlan JS, HilleRisLambers J (2003) Estimating population spread: what can we forecast and how well? Ecology, 84, 1979-1988.

Cook-Patton SC, Lehmann M, Parker JD (in review) Acclimation at the range edge contributes to climate-driven mangrove expansion. Functional Ecology.

Costanza R, d'Arge R, De Groot R et al. (1997) The value of the world's ecosystem services and natural capital. Nature, 387, 253-260.

Dawson TP, Jackson ST, House JI, Prentice IC, Mace GM (2011) Beyond predictions: biodiversity conservation in a changing climate. Science, 332, 53-58.

Duke NC, Ball MC, Ellison JC (1998) Factors influencing biodiversity and distributional gradients in mangroves. Global Ecology and Biogeography Letters, 7, 27-47.

Easterling D, Meehl G, Parmesan C, Changnon S, Karl T, Mearns L (2000) Climate extremes: observations, modeling, and impacts. Science, 289, 2068.

Ellison AM, Bank MS, Clinton BD et al. (2005) Loss of foundation species: consequences for the structure and dynamics of forested ecosystems. Frontiers in Ecology and the Environment, 3, 479-486.

Giri C, Long J, Tieszen L (2011a) Mapping and monitoring Louisiana's mangroves in the aftermath of the 2010 Gulf of Mexico oil spill. Journal of Coastal Research, 27, 1059-1064.

Giri C, Ochieng E, Tieszen L et al. (2011b) Status and distribution of mangrove forests of the world using earth observation satellite data. Global Ecology and Biogeography, 20, 154-159.

Guisan A, Zimmermann NE (2000) Predictive habitat distribution models in ecology. Ecological modelling, 135, 147-186.

Gutschick VP, BassiriRad H (2003) Extreme events as shaping physiology, ecology, and evolution of plants: toward a unified definition and evaluation of their consequences. New Phytologist, 160, 21-42.

IPCC (2012) Managing the risks of extreme events and disasters to advance climate change adaptation. In: A Special Report of Working Groups I and II of the Intergovernmental Panel on Climate Change (eds Field CB, Barros V, Stocker TF, Qin D, Dokken DJ, Ebi KI et al.), pp. 1-19. Cambridge University Press, Cambridge, UK and New York, NY, USA.

Jentsch A, Kreyling J, Beierkuhnlein C (2007) A new generation of climate-change experiments: events, not trends. Frontiers in Ecology and the Environment, 5, 365374.

Kangas PC, Lugo AE (1990) The distribution of mangroves and saltmarsh in Florida. Tropical Ecology, 31, 32-39.
Kearney M, Porter W (2009) Mechanistic niche modelling: combining physiological and spatial data to predict species' ranges. Ecology Letters, 12, 334-350.

Krauss KW, From AS, Doyle TW, Doyle TJ, Barry MJ (2011) Sea-level rise and landscape change influence mangrove encroachment onto marsh in the Ten Thousand Islands region of Florida, USA. Journal of Coastal Conservation, 15, 629-638.

Kreyling J, Jentsch A, Beier C (2014) Beyond realism in climate change experiments: gradient approaches identify thresholds and tipping points. Ecology Letters, 17, 125.

Leuzinger S, Luo Y, Beier C, Dieleman W, Vicca S, Körner C (2011) Do global change experiments overestimate impacts on terrestrial ecosystems? Trends in ecology $\mathcal{E}$ evolution, 26, 236-241.

Lloret F, Peñuelas J, Estiarte M (2005) Effects of vegetation canopy and climate on seedling establishment in Mediterranean shrubland. Journal of Vegetation Science, 16, 67-76.

Lloret F, Escudero A, Iriondo JM, Martínez-Vilalta J, Valladares F (2012) Extreme climatic events and vegetation: the role of stabilizing processes. Global Change Biology, 18, 797-805.

Loik ME, Still CJ, Huxman TE, Harte J (2004) In situ photosynthetic freezing tolerance for plants exposed to a global warming manipulation in the Rocky Mountains, Colorado, USA. New Phytologist, 162, 331-341.

Lonard RI, Judd FW (1991) Comparison of the effects of the severe freezes of 1983 and 1989 on native woody plants in the Lower Rio Grande Valley, Texas. The Southwestern Naturalist, 26, 213-217.

López-Medellín X, Ezcurra E, González-Abraham C, Hak J, Santiago LS, Sickman JO (2011) Oceanographic anomalies and sea-level rise drive mangroves inland in the Pacific coast of Mexico. Journal of Vegetation Science, 22, 143-151.

Markley JL, McMillan C, Thompson GA Jr (1982) Latitudinal differentiation in response to chilling temperatures among populations of three mangroves, Avicennia germinans, Laguncularia racemosa, and Rhizophora mangle, from the western tropical Atlantic and Pacific Panama. Canadian Journal of Botany, 60, 2704-2715.

Maurer EP, Wood AW, Adam JC, Lettenmaier DP, Nijssen B (2002) A long-term hydrologically based dataset of land surface fluxes and states for the conterminous United States*. Journal of Climate, 15, 3237-3251.

Maurer EP, Brekke L, Pruitt T, Duffy PB (2007) Fine-resolution climate projections enhance regional climate change impact studies. Eos, Transactions American Geophysical Union, 88, 504.

Meynard CN, Quinn JF (2007) Predicting species distributions: a critical comparison of the most common statistical models using artificial species. Journal of Biogeography, 34, 1455-1469.

Miller KA, Downton MW (1993) The freeze risk to Florida citrus. I: Investment decisions. Journal of Climate, 6, 354-363.

Montague C, Odum H (1997) The intertidal marshes of Florida's Gulf Coast. In: Ecology and Management of Tidal Marshes: A Model from the Gulf of Mexico (eds Coultas CL, Hsieh Y-P), pp. 1-33. St. Lucie Press, Delray Beach, FL.

Osland MJ, Enwright N, Day RH, Doyle TW (2013) Winter climate change and coastal wetland foundation species: salt marshes vs. mangrove forests in the southeastern United States. Global Change Biology, 19, 1482-1494.

Parmesan C (2006) Ecological and evolutionary responses to recent climate change. Annual Review of Ecology Evolution and Systematics, 37, 637-669.

Pau S, Wolkovich EM, Cook BI et al. (2011) Predicting phenology by integrating ecology, evolution and climate science. Global Change Biology, 17, 3633-3643.

Pérez F, Hinojosa LF, Ossa CG, Campano F, Orrego F (2014) Decoupled evolution of foliar freezing resistance, temperature niche and morphological leaf traits in Chilean Myrceugenia. Journal of Ecology, 102, 972-980.

Pickens CN, Hester MW (2011) Temperature tolerance of early life history stages of black mangrove Avicennia germinans: implications for range expansion. Estuaries and Coasts, 34, 824-830.

Potter KM, Hargrove WW (2013) Quantitative assessment of predicted climate change pressure on North American tree species. Mathematical and Computational Forestry \& Natural-Resource Sciences (MCFNS), 5, 151-169 (118).

Quisthoudt K, Schmitz N, Randin CF, Dahdouh-Guebas F, Robert EM, Koedam N (2012) Temperature variation among mangrove latitudinal range limits worldwide. Trees, 26, 1919-1931.

Rabinowitz D (1978) Dispersal properties of mangrove propagules. Biotropica, 10, 4757.

Record S, Charney N, Zakaria R, Ellison A (2013) Projecting global mangrove species and community distributions under climate change. Ecosphere, 4, art34.

Ridley HN (1930) The Dispersal of Plants Throughout the World. Reeve \& Co., Ashford, UK. 
Rogers K, Wilton K, Saintilan N (2006) Vegetation change and surface elevation dynamics in estuarine wetlands of southeast Australia. Estuarine, Coastal and Shelf Science, 66, 559-569.

Ross MS, Ruiz PL, Sah JP, Hanan EJ (2009) Chilling damage in a changing climate in coastal landscapes of the subtropical zone: a case study from south Florida. Global Change Biology, 15, 1817-1832.

Saintilan N, Wilson NC, Rogers K, Rajkaran A, Krauss KW (2014) Mangrove expansion and salt marsh decline at mangrove poleward limits. Global change biology, 20, $147-157$

Scoccimarro E, Zampieri M, Bellucci A, Navarra A (2013) Heavy precipitation events in a warmer climate: results from CMIP5 models. Journal of Climate, 26, 7902-7911

Sherrod CL, McMillan C (1985) The distributional history and ecology of mangrove vegetation along the northern Gulf of Mexico coastal region. Contributions in Marine Science, 28, 129-140.

Soares MLG, Estrada GCD, Fernandez V, Tognella MMP (2012) Southern limit of the Western South Atlantic mangroves: assessment of the potential effects of global warming from a biogeographical perspective. Estuarine, Coastal, and Shelf Science, 101, 44-53.

Spalding M, Kainuma M, Collins L (2010) World Atlas of Mangroves. Earthscan, New York, NY.

Stevens PW, Fox SL, Montague CL (2006) The interplay between mangroves and saltmarshes at the transition between temperate and subtropical climate in Florida. Wetlands Ecology and Management, 14, 435-444.

Stuart S, Choat B, Martin K, Holbrook N, Ball M (2007) The role of freezing in setting the latitudinal limits of mangrove forests. New Phytologist, 173, 576-583.

Thompson RM, Beardall J, Beringer J, Grace M, Sardina P (2013) Means and extremes: building variability into community-level climate change experiments. Ecology Letters, 16, 799-806.

Williams AA, Eastman SF, Eash-Loucks WE, Kimball ME, Lehmann ML, Parker JD (2014) Record northernmost endemic mangroves on the United States Atlantic coast with a note on latitudinal migration. Southeastern Naturalist, 13, $56-63$
Wilson NC, Saintilan N (2012) Growth of the mangrove species Rhizophora stylosa Griff. at its southern latitudinal limit in eastern Australia. Aquatic Botany, 101, 8-17. Yang S, Logan J, Coffey DL (1995) Mathematical formulae for calculating the base temperature for growing degree days. Agricultural and Forest Meteorology, 74, 6174 .

Zimmermann NE, Yoccoz NG, Edwards TCJ et al. (2009) Climatic extremes improve predictions of spatial patterns of tree species. Proceedings of the National Academy of Sciences, 106, 19723-19728.

\section{Supporting Information}

Additional Supporting Information may be found in the online version of this article:

Figure S1. Map of US southeastern Atlantic coastline showing the modeled current and projected extents of (a) Avicennia germinans, (b) Rhizophora mangle, and (c) Laguncularia racemosa. Projected range limits are based on the mean of the ensemble CMIP 5 RCP 4.5 projections.

Table S1. Correlation coefficients of temperature metrics.

Table S2. Logistic model results for predicting mangrove forest presence using freezing degree days calculated with varying threshold temperatures.

Table S3. Projected range limits for mangrove species from models based on alternative temperature metrics.

Appendix S1. Details about our downscaling methods and use of climate projection models. 